\title{
Preoperative planning for intraoperative navigation guidance
}

\author{
Shahbaaz A. Sabri, Philip J. York \\ Department of Orthopedic Surgery, University of Colorado School of Medicine, Aurora, CO, USA \\ Contributions: (I) Conception and design: All authors; (II) Administrative support: All authors; (III) Provision of study materials or patients: All \\ authors; (IV) Collection and assembly of data: All authors; (V) Data analysis and interpretation: All authors; (VI) Manuscript writing: All authors; (VII) \\ Final approval of manuscript: All authors. \\ Correspondence to: Philip J. York, MD. Department of Orthopedic Surgery, University of Colorado School of Medicine, 12631 E. 17th Ave. Academic \\ Office 1, Mail Stop B202, Aurora, CO 80045, USA. Email: Philip.york@cuanschutz.edu.
}

\begin{abstract}
Intraoperative navigation for spinal procedures has continued to gain popularity. Numerous platforms are currently on the market and offer a spectrum of features. Preoperative considerations when utilizing this technology begin with understanding the fundamental concepts and methods of navigation. Several key factors including patient positioning, reference array placement, and sequence of instrumentation can help improve intraoperative navigation workflow when planned appropriately. The authors review current literature to help guide surgeon decision making when utilizing navigation. Additionally, tips and techniques for use of navigation are detailed to help avoid common surgeon pitfalls. In general, navigation platforms are classified based on image acquisition and degree of surgeon motion restriction during instrumentation. Imageless platforms often require preoperative images to be uploaded into the navigation system. Image-based systems rely on intraoperative imaging to ensure accuracy of its referencing software. The system then creates a three-dimensional model that allows for visualization of the navigated instrument within the surgical field. Active and passive navigation describe the degree of surgeon free-motion restriction when utilizing navigated instruments. Active navigation platforms, such as most robotic systems, prevent the deviation of the surgeon's instrument from a predetermined trajectory. Passive navigation does not restrict surgeon motion and the projected trajectory of the instrumented can be displayed on a three-dimensional model.
\end{abstract}

Keywords: Navigation; O-arm; intraoperative navigation; mobile CT

Submitted Feb 06, 2020. Accepted for publication Jun 11, 2020.

doi: 10.21037/atm-20-1369

View this article at: http://dx.doi.org/10.21037/atm-20-1369

\section{Introduction}

Over the past two decades, CT guided navigation for spinal instrumentation has continued to grow in popularity. Since the introduction of the first mobile CT scanner in the 1990s, the technology has rapidly advanced to allow ease of use for intraoperative applications. Approximately a decade later, open gantry concept 3D imaging (e.g., O-Arm/ Medtronic Sofamor Danek, Inc., Memphis, TN, USA) and table mounted CT scanners (e.g., Airo/Brainlab, Munich, Germany) were developed (1). These smaller machine designs were targeted for use in the operating room and allowed for $3 \mathrm{D}$ navigation for spinal instrumentation
$(1,2)$. Proponents of this technology report decreased OR staff radiation exposure, shorter operative times for spinal instrumentation, and improved accuracy of pedicle screw placement up to $97.5 \%$, as reported by Van de Kelft et al. in their multicenter prospective study $(3,4)$.

Additional imaging devices, such as the Ziehm Vision RFD (Ziehm Imaging, Nuremberg, Germany), have allowed for open-armed machines that provide traditional 2D fluoroscopic imaging in addition to $3 \mathrm{D}$ navigation through the same application. These systems require either a single seamless integration with a particular navigation system (e.g., O-arm/Stealth, Airo/Brainlab, Ziehm/Stryker NAV3i) or can be engineered with a point-to-point registration 
algorithm. Navigation platforms can also be referenced with point-to-point topography via specialized cameras. The navigation is correlated with preoperative imaging (ex. 7D Surgical) or biplanar fluoroscopy overlaid level by level on preoperative CT scans (ex. Globus Excelsius GPS). When utilizing navigation in spine procedures, the surgeon must have a thorough understanding of technologic principles, knowledge of common pitfalls, and a defined preoperative plan to be effective in the operating room.

\section{Fundamental principles}

Preoperative planning for intraoperative navigation guidance requires an understanding of a number of basic concepts that translate across this technology along with various methods of navigation available for spinal procedures. In broad terms, navigation systems rely on either an imageless or image-based system (fluoroscopy, CT scan). The system is further delineated as an active or passive navigation platform. Imageless navigation functions via optical markers placed on known anatomic landmarks which are recognized by a navigation camera $(3,5)$. Typically, imageless systems reference the optical markers with a previously uploaded preoperative CT. The navigation computer creates a virtual 3D model which can be viewed intraoperatively. Although based on surgeon preference and navigation platform, navigation guidance is generally visualized along an axial, sagittal, and coronal plane.

In a similar way, 3D fluoroscopy and intraoperative CTbased navigation require markers to be placed either within the field of imaging or on anatomic landmarks that can be viewed by an optical camera or sensor. Imaging is then obtained intraoperatively. The system spatially references navigated instruments with the static markers. With CT or $3 \mathrm{D}$ imaging platforms, the data can be reformatted and viewed to provide real time navigation for the operating surgeon $(3,6,7)$.

Active or passive navigation refers to the method and degree of surgeon motion restriction during instrumentation. Passive navigation platforms provide the surgeon strictly with image guidance when viewing proposed trajectories of navigated surgical instruments. No method of motion restriction occurs during instrumentation. When considering active navigation platforms, surgical instruments are guided in a predetermined path or trajectory through external measures: customized cutting jigs, drill guides, robotic arm assistance $(5,6)$. For example, patient specific pedicle screw drill guides can be created from a preoperatively obtained CT or MRI scan. This requires preoperative screw trajectory planning which is sent to the company to fabricate the sterile custom drill guides. Intraoperatively, the custom drill guides are placed on the intended vertebral level and aligned based on the patient's bony anatomy. The surgeon must confirm that the drill guide is fitted appropriately to the predefined anatomical landmarks. Finally, the surgeon drills the predetermined screw trajectory, the jig is removed, and the pedicle screw is placed (Firefly/Mighty Oak Medical, Englewood, CO, USA). The theoretical benefit of this type of process is the reduction of additional intraoperative radiation, such as pediatric deformity cases and other situations in which additional radiation should be limited.

\section{Intraoperative navigation}

Planning for intraoperative use of navigation must take into account the imaging system and navigation platform available at the surgeon's facility. Use of active navigation without intraoperative CT imaging has been shown as a viable and cost-effective alternative to passive image-based $3 \mathrm{D}$ navigation platforms (8). Utilizing preoperative CT based drill guides, Sugawara et al. reported $98.5 \%$ accuracy with screw placement in the cervicothoracic spine (9). Similarly, Fan et al. performed a recent meta-analysis of ten RCTs and two prospective cohort studies evaluating patient-specific pedicle screw guides. They concluded superior pedicle screw accuracy with this form of active navigation when compared to free hand technique (10). It is Important to note, use of referencing drill guides requires the surgeon to visually confirm anatomic landmarks when using this technique.

In contrast to active navigation, passive $3 \mathrm{D}$ navigation platforms offer a greater variety of use in spinal procedures such as open and minimally invasive instrumentation, interbody fusion, spine tumor resection, and intraoperative $3 \mathrm{D}$ evaluation of osteotomies for spinal deformity correction $(11,12)$. These platforms do not require extensive preoperative planning and there is no wait time for the drill guide development. This benefit with passive $3 \mathrm{D}$ navigation helps facilitate use in urgent, emergent, or trauma procedures. However, a relatively steep learning curve and surgeon reluctance due high cost, lack of equipment, or inadequate technology training with $3 \mathrm{D}$ navigation have been described (13-15). Appropriate surgeon and staff training, effective preoperative planning, and avoiding initial pitfalls can aid a surgeon when performing procedures with 
this technology.

\section{Planning for intraoperative navigation}

When incorporating intraoperative navigation into OR workflow, effective preoperative planning can often mitigate common logistic pitfalls. Rahmathulla et al. described their institution's experience with the $\mathrm{O}$-arm and suggest an algorithm based on surgical region of the spinal procedure (15). They report several critical factors which should be planned preoperatively when using 3D navigation: bed selection, patient positioning, OR room setup, and location of digital reference arrays. Patient habitus and specific image gantry dimensions should be considered as well.

Currently, several intraoperative navigation options exist, and the operating surgeon should be aware of the size limitations of the imaging device in use. For example, the inner diameter of the O-arm (Medtronic Sofamor Danek, Inc., Memphis, TN, USA) measures $70 \mathrm{~cm}$ with a telescoping feature allowing lateral patient access (2). The patient, OR table, and arm boards must be within this diameter in order for imaging and ease of use with $3 \mathrm{D}$ navigation. In regard to patient positioning for intraoperative navigation with open gantry scanners (e.g., O-Arm/Medtronic Sofamor Danek, Inc., Memphis, TN, USA), our institution's experience reveals improved OR workflow when the patient's arm positioning is determined by location of the surgical procedure. For example, O-arm scans can be expedited if patient arms are tucked rather than placed on arm boards for cervical, thoracic, and deformity procedures. For strictly lumbar, lumbosacral, or lateral procedures, use of arm boards generally does not interfere with $\mathrm{O}$-arm scans and navigation capability $(4,16)$.

Placement of the reference array requires thoughtful planning prior to incision. Depending on type of procedure (open $v s$. percutaneous), location (cervical, thoracic, lumbar), and number of levels requiring instrumentation, the surgeon may choose a spinous process clamp, iliac wing or PSIS pins, or prior fusion rod fixation of the reference frame array clamp $(15,16)$. While a majority of the navigation platforms require a reference array attached to bone, there are other alternatives. NAV3i (Stryker, Kalamazoo, MI, USA) allows for bone anchored and skinbased arrays. Both SpineMask and CranialMap technology (Stryker, Kalamazoo, MI, USA) utilize an array of LED lights adhered to the skin either nearby or surrounding the area of interest.

For cervical procedures, reference arrays may also be rigidly attached to the Mayfield head holder. This array placement can be helpful when performing single level procedures such as C1-2 posterior fusion where it might be detrimental to extend the surgical exposure simply to place a reference clamp at a distal level. After placement of the digital array, it should be tested to ensure rigid fixation. If not secure, motion can occur during the procedure resulting in dangerous inaccuracies with navigated instruments.

It is important to understand that the proximity of the reference array to the levels being instrumented affects accuracy. For example, percutaneous pelvic reference arrays cannot accurately provide a reference point for thoracic instrumentation. When performing deformity procedures requiring extensive instrumentation, consideration should be given to using two fixed reference arrays in closer proximity to cranial and caudal levels (17). Scheufler $e t$ al. demonstrated a gradual rise in screw misplacement rate with increasing distance between an instrumented vertebra and the reference array beyond 11 segments (17). Additionally, Rahmathulla et al. recommend decreasing the risk of navigation inaccuracy by starting instrumentation at levels furthest away from the reference array. This is especially important in cases of navigating interbody placement such as navigated lateral procedures where the anatomy is altered with each interbody placement.

For lateral interbody fusion procedures at our institution, the reference array is usually placed via a bicortical pin in the iliac wing. The most cephalad interbody segment (furthest away from the frame) is instrumented first. Subsequent levels are addressed moving in caudal direction toward the navigation array. As the interbody devices are placed, the anatomy proximal to the interbody is altered relative to the frame; however, the distal anatomy remains relatively constant to the navigation array fixed on the iliac wing. Importantly, the surgeon must be vigilant of changes that can occur during the procedure affecting accuracy of the navigation. There should be a low threshold to confirm the navigation against known surface anatomy.

\section{Conclusions}

Intraoperative navigation has continued an upward trend in popularity and surgeon acceptance. This technology is an adjuvant when treating spinal disorders in a safe and efficient manner; however, it does not replace the intricate knowledge of anatomy or surgeon experience. Furthermore, image guided approaches to spinal instrumentation build upon the fundamentals of free-hand techniques. Surgeons 
must be able to recognize instances where the navigation has been altered or is inaccurate. Ultimately, spine surgeons should have the training and abilities necessary to place screws and interbody devices safely with alternative techniques in case the navigation is not available or malfunctioning. Careful preoperative planning is necessary to enhance intraoperative navigation workflow and improve surgical outcomes.

\section{Acknowledgments}

The authors thank Nadia Sabri, MD for intellectual discussion and manuscript support.

Funding: None.

\section{Footnote}

Provenance and Peer Review: This article was commissioned by the Guest Editor (Dr. Sheeraz Qureshi) for the series "Current State of Intraoperative Imaging" published in Annals of Translational Medicine. The article was sent for external peer review organized by the Guest Editor and the editorial office.

Conflicts of Interest: Both authors have completed the ICMJE uniform disclosure form (available at http://dx.doi. org/10.21037/atm-20-1369). The series "Current State of Intraoperative Imaging" was commissioned by the editorial office without any funding or sponsorship. PJY reports personal fees from Depuy-Synthes, outside the submitted work. The authors have no other conflicts of interest to declare.

Ethical Statement: The authors are accountable for all aspects of the work in ensuring that questions related to the accuracy or integrity of any part of the work are appropriately investigated and resolved.

Open Access Statement: This is an Open Access article distributed in accordance with the Creative Commons Attribution-NonCommercial-NoDerivs 4.0 International License (CC BY-NC-ND 4.0), which permits the noncommercial replication and distribution of the article with the strict proviso that no changes or edits are made and the original work is properly cited (including links to both the formal publication through the relevant DOI and the license). See: https://creativecommons.org/licenses/by-nc-nd/4.0/.

\section{References}

1. Adamczak SE, Bova FJ, Hoh DJ. Intraoperative 3D Computed Tomography: Spine Surgery. Neurosurg Clin N Am 2017;28:585-94.

2. Sembrano JN, Santos ER, Polly DW Jr. New generation intraoperative three-dimensional imaging (O-arm) in 100 spine surgeries: does it change the surgical procedure? J Clin Neurosci 2014;21:225-31.

3. Karkenny AJ, Mendelis JR, Geller DS, et al. The Role of Intraoperative Navigation in Orthopaedic Surgery. J Am Acad Orthop Surg 2019;27:e849-58.

4. Kleck CJ, Cullilmore I, LaFleur M, et al. A new 3-dimensional method for measuring precision in surgical navigation and methods to optimize navigation accuracy. Eur Spine J 2016;25:1764-74.

5. Musahl V, Plakseychuk A, Fu FH. Current opinion on computer-aided surgical navigation and robotics: role in the treatment of sports-related injuries. Sports Med 2002;32:809-18.

6. Qureshi S, Lu Y, McAnany S, et al. Three-dimensional Intraoperative Imaging Modalities in Orthopaedic Surgery: A Narrative Review. J Am Acad Orthop Surg 2014;22:800-9.

7. Holly LT, Foley KT. Intraoperative spinal navigation. Spine (Phila Pa 1976) 2003;28:S54-S61.

8. Chen PC, Chang CC, Chen HT, et al. The Accuracy of 3D Printing Assistance in the Spinal Deformity Surgery. Biomed Res Int 2019;2019:7196528.

9. Sugawara T, Kaneyama S, Higashiyama N, et al. Prospective Multicenter Study of a Multistep Screw Insertion Technique Using Patient-Specific Screw Guide Templates for the Cervical and Thoracic Spine. Spine (Phila Pa 1976) 2018;43:1685-94.

10. Fan Y, Du JP, Wu QN, et al. Accuracy of a patient-specific template for pedicle screw placement compared with a conventional method: a meta-analysis. Arch Orthop Trauma Surg 2017;137:1641-9.

11. Kelly PD, Zuckerman SL, Yamada Y, et al. Image guidance in spine tumor surgery. Neurosurg Rev 2020;43:1007-17.

12. Fujibayashi S, Neo M, Takemoto M, et al. Computerassisted spinal osteotomy: a technical note and report of four cases. Spine (Phila Pa 1976) 2010;35:E895-E903.

13. Härtl R, Lam KS, Wang J, et al. Worldwide survey on the use of navigation in spine surgery. World Neurosurg 2013;79:162-72.

14. Sasso RC, Garrido BJ. Computer-assisted spinal navigation 
versus serial radiography and operative time for posterior spinal fusion at L5-S1. J Spinal Disord Tech 2007;20:118-22.

15. Rahmathulla G, Nottmeier EW, Pirris SM, et al. Intraoperative image-guided spinal navigation: technical pitfalls and their avoidance. Neurosurg Focus 2014;36:E3.

16. Kleck CJ, Johnson C, Akiyama M, et al. One-step Minimally Invasive Pedicle Screw Instrumentation

Cite this article as: Sabri SA, York PJ. Preoperative planning for intraoperative navigation guidance. Ann Transl Med 2021;9(1):87. doi: 10.21037/atm-20-1369
Using O-Arm and Stealth Navigation. Clin Spine Surg 2018;31:197-202.

17. Scheufler KM, Franke J, Eckardt A, et al. Accuracy of image-guided pedicle screw placement using intraoperative computed tomography-based navigation with automated referencing. Part II: thoracolumbar spine. Neurosurgery 2011;69:1307-16. 